\title{
RECORDS TO MAKE ABORIGINALITY COUNT
}

A boriginality is poorly recorded in the three Statewide health data collections in NSW mortality, hospital inpatient and midwives - that routinely provide the main information on deaths. The major problem, according to Gray and Hogg, is under-enumeration. They found that 33 per cent of the 315 deaths of Aboriginal people identified in a study in rural NSW had not been coded as such in official births, deaths and marriages records.

\section{ABORIGINAL MORTALITY DATABASE}

The most accurate information about Aboriginal mortality has come from individual studies of specific communities. Recent studies have documented the persistently poor health status of Aboriginal Australians compared to the nonAboriginal population (for example, Khalidi, 1989²; Gray and Hogg, ibid.). Such studies tend to be timeconsuming and resource-intensive. They deal with specific (usually geographically) defined populations and relate to deaths over an earlier, rather than current time.

As a result of their 1989 study, Gray and Hogg made several recommendations for improving the data on Aboriginal mortality in NSW. Their report was released as public health was being strengthened in NSW, including the establishment of an Epidemiology Branch within the Health Department which undertook to improve the enumeration of Aboriginal mortality in NSW.

We found that Aboriginal health workers in rural areas of NSW were already using a special form to notify the deaths of Aboriginal people to the Aboriginal Health Unit of the Health Department, thus providing a continuing but under-utilised source of data not readily available elsewhere. Aboriginal health workers at all levels were keen to retain the existing reporting system, with some modifications. The form was revised in consultation with the Aboriginal health workers and now records date of death, age at death, where the person died, where the person lived, sex, main cause of death, contributing conditions, whether there was an accident or violence involved (the latter three coded by ICD-9).

Copies of the form (minus identity) are forwarded to the Epidemiology Branch and will be used to prepare regular statistical statements on Aboriginal mortality. The new reporting system will cover deaths from October 1, 1990. The objectives of the enhanced reporting system are to improve the enumeration of Aboriginal deaths, provide Aboriginal health workers with a regular statement about deaths in their area and promote the health concerns of Aboriginal people.

In the first instance the collection is unlikely to be complete: it will include only deaths of which the health workers are aware and forms will be returned only from areas where there are State health workers. We anticipate that deaths in urban Aboriginal communities will be under-represented on the register, but we plan to tackle this problem by approaching other Aboriginal health services to participate in the reporting system. Future work will concentrate on other issues central to setting up a death reporting system, including defining denominator populations, validation of death data, and cross-referencing the collection with births, deaths and marriages data.

Judith E. Jones and David Lyle, Epidemiology and Health Services Evaluation Branch, and Liz Williams, Aboriginal Health Unit, NSW Health Department.

\footnotetext{
We are grateful for the assistance of the Aboriginal Unit, NSW Heclth Department and the Senior Aboriginal Health Workers throughout New South Wales in revising and implementing the reporting system.

1. ' GRAY A and HOGG R. Mortality of Aboriginal Australians in Western New South Wales 1984-87. New South Wales Department of Health, Sydney, 1989.

2. KHALIDI NA. Aboriginal mortality in central Australia, 1975-77 to

1985-86: a comparative analysis of levels and trends. The Australian National University, Canberra, 1989.
}

\section{Keeping Tabs on Toxic Substances}

- Continued from page 18

\section{EDITORIAL COMMENT}

Assessment and management of the risks posed by community exposures to any of the estimated 65,000 chemicals in industrial and domestic use in Australia is very complex. Comprehensive toxicological information is available for only a minority of the chemicals. Increasingly, the desires of "modern, literate and socially enfranchised communities to take greater control of their own social environment and health" lead to questioning of the assumptions underlying risk assessment and risk management practices. Toxicology is the fundamental science which informs these debates.

Regulatory toxicology, the branch of this science practised by the Toxicology Unit in the NSW Health Department, will face several critical issues in the coming decade. The role of quantitative risk assessment in the management of environmental health issues and the effectiveness of risk communication are two examples. Also, developments within the public health infrastructure will enable the Unit to participate in ad hoc studies in environmental health and in the analysis and interpretation of routinely collected cancer and birth defects data.

1. McMichael T Social Justice and World Health In Touch 7:4, pp 3 